\title{
Spinal Cord Injury and its Impact on the Patient, Family, and the Society
}

\author{
${ }^{1}$ Harvinder Singh Chhabra, ${ }^{2}$ Sahil Batra
}

How to cite this article: Chhabra HS, Batra S. Spinal Cord Injury and its Impact on the Patient, Family, and the Society. Int J Recent Surg Med Sci 2016;2(1):1-4.

\section{Source of support: Nil}

\section{Conflict of interest: None}

Spinal cord injury (SCI) is a complex and life-changing disease. Spinal cord injury encompasses damage to the spinal cord from traumatic or nontraumatic causes. Spinal cord injury includes a whole spectrum from a child born with spina bifida to an old person who develops SCI as a result of osteoporosis or a tumor. Spinal cord injury may happen to a construction worker who falls from scaffolding and to a victim of conflict or gun violence.

\section{Medical/Physical Consequences}

Spinal cord injury has significant medical/physical consequences, leaving the individual paralyzed below the level of the injury (tetraplegic or paraplegic). Acute management is very challenging, posing significant risk to life. It involves appropriate prehospital care (evacuation from site of accident, first aid at site, and transfer to medical facility) and subsequently on reaching the hospital, an appropriate emergency management, comprehensive evaluation, conservative/surgical management of vertebral fracture, and prevention as well as management of complications. Once the fracture is stabilized, relevant acute and postacute medical care, and rehabilitation services must be accessible to ensure maximal function so that the individual can be as independent as possible. Different models of service delivery are available, but centers specialized in SCI management have been shown to reduce costs and result in fewer complications with lower rehospitalization rate in comparison to nonspecialized centers.

${ }^{1}$ Orthopedist and Surgeon, ${ }^{2}$ Fellow and Junior Consultant

${ }^{1}$ Department of Spine Services, Indian Spinal Injuries Centre Vasant Kunj, New Delhi, India

${ }^{2}$ Department of Clinical Research, Indian Spinal Injuries Centre Vasant Kunj, New Delhi, India

Corresponding Author: Harvinder Singh Chhabra, Orthopedist and Surgeon, Department of Spine Services, Indian Spinal Injuries Centre, Vasant Kunj, New Delhi, India, e-mail: drhs chhabra@isiconline.org
The highest priority for a person with SCI is to achieve a good control of bladder and bowel function to prevent any social embarrassment. Regular physiotherapy and occupational therapy can help to maximize function in lower and upper limbs respectively. Following the defined guidelines, techniques for achieving independence in everyday activities can be taught to a person with SCI depending on his/her neurological level. The level of independence a person with SCI achieves may change with time depending on motor recovery in cases of incomplete SCIs. Even a single root recovery can contribute significantly to make a tetraplegic patient independent in activities of daily living, with a proper guidance. For example, recovery of $\mathrm{C} 7$ root with a good triceps function can significantly aid in transfers.

A multidisciplinary approach is needed for managing a person with SCI. Other than the doctor, nurse, physiotherapist, and occupational therapist, various other team members are involved in SCI management. A psychologist and mental health services team, including peer counselors specialized in dealing with people with SCI, can help to deal with the depression and other psychological trauma due to the disease and disability. Depression is known to decrease the expected recovery of function and leads to an increase in complication rate after discharge from the proper care. An urologist, or a sexual counselor, or paramedical personnel should be involved with a person with SCI to resolve all the doubts related to sexual and reproductive ability of the individual. A proper therapeutic management with a good counseling can help people with SCI to sustain their personal relationship with their partners and have a family. An assistive technology (AT) specialist is a vital component of the team because majority of people with SCI would require some form of wheelchair which could be tailormade for the patient as per his/her needs, living place, and neurological level. The AT specialist would help the family of a spinal cord injured person to modify the home and its surroundings so that they could access all the possible things in the home so that they may feel independent. A social services team would help the individual know their rights as an employee and an individual and help them return back to education and employment. All these measures can ensure that children and adults with SCI can return to study, be independent, make an economic participation, and contribute to family and community. 
Despite the increasing incidence of rehabilitation facilities available across the globe, there is paucity of specialized centers for making people with SCI as independent as possible. The awareness for their inclusion into the society and vocation is lacking among individual, families, and even the professionals managing these injuries at nonspecialized centers. There is a dearth of trained personnel, modified equipments, and assistive devices in majority of places in less developed nations, including India. There are minimal facilities for the people with disability with modified or partial independence to be able to use public transport or recreational facilities in the majority of less developed nations. Even majority of the nursing homes across the country like India lacks the infrastructure for a person with SCI to be independent in the hospital area.

\section{Psychosocial Impact}

Spinal cord injury has a life-disturbing impact on physical, mental, and social behavior of a person. The impact is not only limited to the individual but also affects the family and the society as well. The incidence for the mental disorders is very high reaching up to 20 to $25 \%$ for an anxiety disorder $^{1}$ and 30 to $40 \%$ for a depressive disorder. ${ }^{2}$ The development of characteristic mental and physical symptoms after exposure to an extreme traumatic experience has been described under the name posttraumatic stress disorder (PTSD). Post-traumatic stress disorder is very common after SCI and the incidence ranges from 10 to $40 \%$ in the literature. ${ }^{3}$ Such variation in the literature may probably be explained because of the variation in quality of psychological team around the globe. Spinal cord injury affects the psychology of the patient to an extent that they have sleep disturbances like restless sleep, difficulty in initiating and maintaining sleep, snoring, often awaking in the early hours of the morning. ${ }^{4}$

Spinal cord injury affects the whole family. Family members may feel as frightened, worried, and overwhelmed as the patient. It takes a few months or a year or two before everybody in the family adapts and adjusts to the drastic changes in roles, responsibilities, finances, and priorities. The near and dear of the people with SCI are the ones providing personal care for the individual with a disability, especially in less developed nations where majority of the people would not afford a specialized caregiver. However, whenever possible, it is desirable to have a trained person for most of the care of the individual, depending on the disability and independence of the individual. There is a separate role for every individual in the family, be it a parent or a partner. Being a caregiver, or a partner, or parent can lead to a blurring of roles which can put a strain on the relationships in the long term.

Various misconceptions about the SCI and negative attitudes of the unaware society and individual lead to exclusion of many people from full participation in society. From a child with SCI who has a less likelihood of starting school than his peers and less likely to advance after enrollment to an adult who will get a lesser priority than his peers for employment, people with SCI face a social outcast at all ages.

\section{Family Breakdown}

Spinal cord injury can have a negative impact on personal relationships and is associated with a higher rate of divorce. The partner tends to get frustrated with the relationship over a period of time, especially if he/she is playing the role of a caregiver too. Spinal cord injury affects both genital and sexual functioning. ${ }^{5}$ Forty-two percent of males with $\mathrm{SCI}$ are not satisfied with their sex lives. ${ }^{6}$ Thirty-four percent of SCI patients are not satisfied with their partner relationships. ${ }^{7}$ Caregivers of children and young people with spina bifida or traumatic SCI experience isolation and stress. This leads to burn out of their love for the individual with SCI in many cases, which may explain separation of many couples after the injury.

\section{Continuous Health Care}

People with SCI are potentially at risk for recurrent urinary tract infections, pressure sores, deep vein thrombosis, osteoporosis, chest infections, and sepsis. These complications can be prevented by spreading awareness among individuals and the caregivers. Despite taking all the precautions, there is a narrow margin for error for these patients. The constant risk of a complication leads to insecurity among these patients and a disturbed mental state. The recurrent problems and a regular checkup to prevent any complication lead to a higher cost for the treatment. The family and the society also start drifting away from people with SCI due to ongoing medical issues and disability. There are reports showing higher incidence of premature mortality in persons with $\mathrm{SCI}$, with the highest incidence being in the first year after SCI. ${ }^{8}$

\section{Need for a Caregiver}

A person with SCI would always be partially or completely dependent on someone for performing some or all activities in his/her daily routine depending on the level of injury. The best of the SCI centers having best of the facilities are still facing challenges to make the spinal cord injured person completely independent. A caregiver is a person who stays with the spinal cord injured person and assists him/her in being as independent as he/she can be and still carry out all the daily routine activities. The caregiver can be a family member or a hired personnel who has been trained to carry out the job. 
This has a financial impact on the family and the person with SCI who is still not employed and earning. Also, if a family member acts as a caregiver, this will influence his schedule, activities, and relationships outside the home. ${ }^{9}$

\section{Lower Participation in School}

Children and young people with spina bifida or acquired SCI are less likely to attend school and less likely to participate in tertiary education. They face hurdles in advancing in school to be able to enroll for tertiary education, and once they are educated, they face similar or more obstacles in procuring a job. ${ }^{10}$ With the family support and a good psychologist and advances in the technology, persons with SCI are able to foresee the employment opportunities which increases the motivation to participate in school and higher education. The awareness among people and the role of social services team in spreading the awareness of the rights of people with SCI and residual disability have helped many people with SCI to get equal employment opportunities. But the incidence of such occurrences is still rare in comparison to the number of persons with SCI.

\section{Lower Return to Work Rates}

Average global employment rates for people with SCI are only $37 \%$, with a high of $51 \%$ in Europe. ${ }^{11}$ Majority of the persons with SCI are not able to physically or mentally adapt to a pre-SCI work status. Many of these do not try to procure or apply for their old jobs and many of whom apply will not be hired. There are available rights of an employee, which majority of people are unaware of. Persons with SCI should be made aware of their rights and should be rehabilitated back to their original or modified employment.

\section{Significant Economic Consequences}

Costs of SCI are higher than for comparable conditions, such as dementia, multiple sclerosis, cerebral palsy, and bipolar disorder. People who are not able to afford the acute care and are not able to carry out the regular follow-up and treatment of the complications usually succumb to the disease and have a higher mortality rate. In Australia, the lifetime costs (including the financial costs and burden-of-disease costs) were estimated to be AUS $\$ 5$ million for a person with paraplegia and AUS $\$ 9.5$ million for a person with tetraplegia. ${ }^{12}$ Indirect costs, such as lost earnings, generally exceed direct costs.

\section{Lack of Information}

Rehabilitation providers may lack knowledge and skills relevant to SCI. Lack of expertise among various members of the team managing a spinal cord injured can cause various hurdles in achieving a desired independence. An improperly designed wheelchair or assistive device can worsen the life of a spinal cord injured. The unawareness about the preventable secondary complications of SCI among the staff managing the spinal cord injured can increase the number of complications and under diagnosis of the complications. Also the guidelines have to be followed for the management of the complications, if anything happens. Specialized centers should follow the current guidelines for management of various complications and should timely evolve with any changes in the management as per the literature.

\section{Physical Access Barriers}

Homes, schools, workplaces, and even hospitals are often inaccessible to people who use wheelchairs. ${ }^{13}$ Being not able to use public or personal transport is a major hurdle in social participation, particularly for those who live in rural areas. This prevents people with SCI leaving hospital or nursing home and becoming independent. There are many reforms needed, especially in less developed nations to provide a better opportunity to persons with SCI so that they can be independent in and out of their homes. This adds to the cost for the family. Also, if these modifications are not done, a person with SCI will always require a caregiver for some or other of his daily routine activities, which affects the individual as well as the family.

\section{Negative Attitudes}

The false perception that tetraplegia is a fate worse than death, or that people in wheelchairs cannot work or cannot have intimate relations is widespread. Even family members and the loved ones may have negative attitudes and low expectations. This is due to the lack of knowledge among people. There is a need for special awareness programs to spread the message among masses that "A person with SCI who has access to health care, personal assistance if required, and assistive devices should be able to return to study, live independently, make an economic contribution, and participate in family and community life."

\section{Recommendations}

Spinal cord injury is both a public health and human rights challenge. With the availability and implementation of the right policies, a person with SCI can live, thrive, and contribute to the family and community, fairly independently. People with SCI are people with disabilities, and they are entitled to the same human rights and respect as all other people with disabilities. Once a person 
with SCI has had their immediate health needs met, social and environmental barriers are the main obstacles to successful functioning and inclusion in society. It is essential to ensure that health services, education, transport, and employment are available and accessible to people with SCI, alongside other people with disabilities. Spinal cord injury will always be a life-changing event, but it need not be a tragedy and a burden.

Addressing the following issues are especially important: ${ }^{10}$

- Appropriate prehospital care is vital for immediate survival.

- Improve health sector response to SCI.

- Empower people with SCI and their families.

- Support for family members and other caregivers can prevent stress and burnout.

- Community-based rehabilitation is important in lowincome settings.

- Challenge negative attitudes to people with SCI.

- Ensure that buildings, transport, and information are accessible.

- Support vocational training, employment, and self-employment.

Realizing the need for creating awareness about prevention of SCI and the fact that spinal injury can lead to a fully inclusive life if managed appropriately, International Spinal Cord Society has decided to launch an international campaign to observe 5th September as a SCI Day (more information on www. worldsci day.org).

\section{REFERENCES}

1. Kennedy P, Rogers BA. Anxiety and depression after spinal cord injury: a longitudinal analysis. Arch Phys Med Rehabil 2000 Jul;81(7):932-937.

2. Kennedy P, Duff J. Post-traumatic stress disorder and spinal cord injuries. Spinal Cord 2001 Jan;39(1):1-10.
3. Gill M. Psychosocial implications of spinal cord injury. Crit Care Nurs Q 1999 Aug;22(2):1-7.

4. Bonekat HW, Andersen G, Squires J. Obstructive disordered breathing during sleep in patients with spinal cord injury. Paraplegia 1990 Jul;28(6):392-398.

5. Siosteen A, Lundquist C, Blomstrand C, Sullivan L, Sullivan M. Sexual ability, activity, attitudes and satisfaction as part of adjustment in spinal cord-injured subjects. Paraplegia 1990 Jul;28(5):285-295.

6. Phleps G, Brown M, Chen J, Dunn M, Lloyd E, Stefanick ML, Davidson JM, Perkash I. Sexual experience and plasma testosterone levels in male veterans after spinal cord injury. Arch Phys Med Rehabil 1983 Feb;64(2):47-52.

7. Franceschini M, Di Clemente B, Rampello A, Nora M, Spizzichino L. Longitudinal outcome 6 years after spinal cord injury. Spinal Cord 2003 May;41(5):280-285.

8. Lidal IB, Snekkevik H, Aamodt G, Hjeltnes N, BieringSørensen F, Stanghelle JK. Mortality after spinal cord injury in Norway. J Rehabil Med 2007 Mar;39(2):145-151.

9. Ducharme S, Parashar D. Psychosocial adjustment to spinal cord injury for individuals and families. Chapter 43. In: Chhabra HS, editor. ISCoS textbook on comprehensive management of spinal cord injuries. 1st ed. Philadelphia (PA): Lippincott Williams and Wilkins; 2015. p. 679-689.

10. WHO and ISCoS summary on International perspectives on spinal cord injury. Available from: http://www.who.int/ disabilities/policies/spinal_cord_injury/report/en/.

11. Young AE, Murphy GC. Employment status after spinal cord injury (1992-2005): A review with implications for interpretation, evaluation, further research, and clinical practice. Int J Rehabil Res 2009 Mar;32(1):1-11.

12. Access Economics for the Victorian Neurotrauma Initiative. The economic cost of spinal cord injury and traumatic brain injury in Australia. 2009 [accessed 2013 Jan 9]. Available from: http://www.tac.vic.gov.au/about-the-tac/ our-organisation/research/tac-neurotrauma-research/ vni/the20economic20 cost20of20spinal-20cord20injury20 and20traumatic20brain20injury20in20australia.pdf.

13. Psychosocial Adjustment to Spinal Cord Injury. 2012. Available from: www.elearnsci.org. http://www.elearnsci. org $/$ module.aspx?id $=160 \&$ category $=$ Psychologists $\% 2 c+$ Social+Workers+and + Peer + Counsellors \&module $=$ Psychos ocial+Adjustment+to+SCI\&lesson=Overview. 